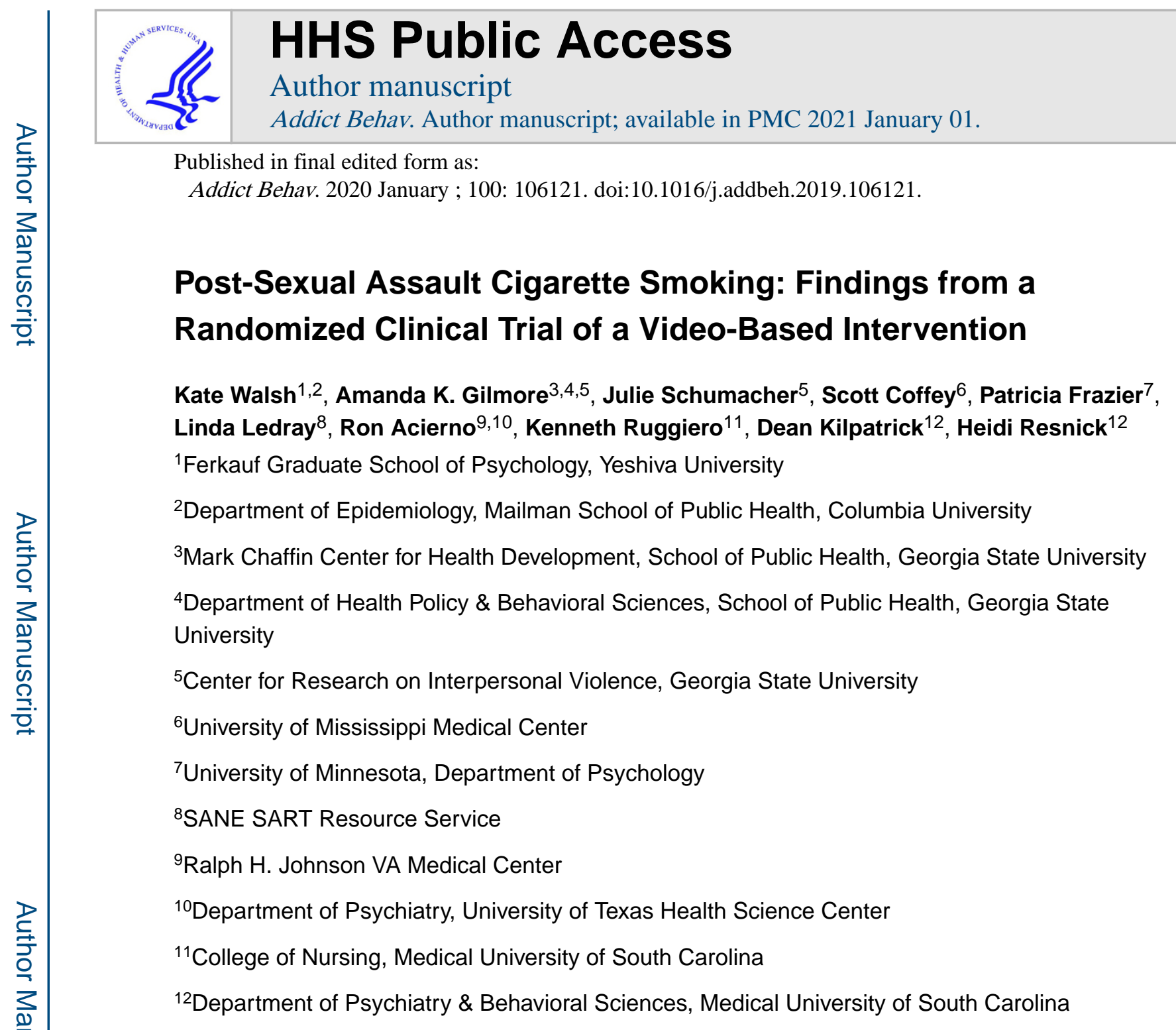

\title{
Abstract
}

Sexual assault (SA) is associated with elevated risk for cigarette smoking. The current study tested whether a brief video intervention delivered in the emergency department was effective at reducing smoking following SA. Participants were 233 girls and women (age 15+) who received a SA medical forensic examination (SAMFE) and were randomized to one of three conditions: 1 ) Prevention of Post-Rape Stress (PPRS), a brief video designed to reduce post-SA psychopathology; 2) Pleasant Imagery and Relaxation Information (PIRI), an active control video

\footnotetext{
Corresponding Author: Kate Walsh, PhD, Ferkauf Graduate School of Psychology, Yeshiva University, 1165 Morris Park Ave, Bronx, NY 10461; Telephone: 646-592-4509; Fax: 718-430-3850; kate.walsh@yu.edu.

Contributors

The first author analyzed the data and drafted the manuscript; middle authors assisted with study development, including questionnaire selection and assessment timing, reviewing and providing feedback on drafts of the manuscript, and approving the final version for publication; and the final/senior author designed the study, obtained funding and IRB approval, cleaned the data, aided with the conceptualization and writing of the manuscript, and reviewed multiple drafts and provided feedback.

Publisher's Disclaimer: This is a PDF file of an unedited manuscript that has been accepted for publication. As a service to our customers we are providing this early version of the manuscript. The manuscript will undergo copyediting, typesetting, and review of the resulting proof before it is published in its final form. Please note that during the production process errors may be discovered which could affect the content, and all legal disclaimers that apply to the journal pertain.

Conflicts of Interest

The authors have no conflicts of interest to declare.
} 
involving relaxation training; and 3) treatment as usual (TAU). Among those who participated at baseline, 154 participants completed at least one follow-up at 1.5, 3, and 6 months after the SAMFE. Participants reported the number of days of smoking and the average number of cigarettes smoked per day in the two weeks prior to the sexual assault as well as in the two weeks prior to each follow-up. Two-thirds (68.8\%) of participants smoked prior to the SA or during any follow-up. One-fifth of participants who did not smoke prior to the SA smoked at one or more follow-ups. Smoking declined on average over follow-up although TAU was associated with increased initial smoking compared to PPRS; PPRS and PIRI did not differ. SA contributes to increases in smoking and the PPRS, a brief and cost-effective video-based intervention delivered during the SAMFE, can protect against increases in post-SA smoking.

\section{Trial registration:}

\section{Keywords}

smoking; sexual assault; emergency department; brief intervention; randomized controlled trial

\section{INTRODUCTION}

Cigarette smoking is the leading cause of preventable death in the United States (Health \& Services, 2014; Jamal, 2016); thus, identifying individuals at heightened risk for smoking and intervening early is of paramount importance. In representative samples, rates of smoking are elevated among individuals exposed to trauma (Hapke et al., 2005; Roberts, Fuemmeler, McClernon, \& Beckham, 2008; Walsh et al., 2014). For example, among New York City residents exposed to the September 11 terrorist attacks, nearly $10 \%$ of the sample reported an increase in smoking in the month following the attacks compared to the month prior to the attacks (Vlahov et al., 2004). Interpersonal and assaultive violence including adverse childhood experiences (ACEs) and physical and sexual assault are especially potent predictors of smoking during adolescence and adulthood (Anda et al., 1999; Cisler et al., 2011; Edwards, Anda, Gu, Dube, \& Felitti, 2007; Ford et al., 2011; Nemeth, Bonomi, Lu, Lomax, \& Wewers, 2016). In fact, women who have experienced sexual assault (SA) are roughly twice as likely as those without a history to report any lifetime cigarette smoking (Cloutier, Martin, \& Poole, 2002; Matthews et al., 2017; Nemeth et al., 2016; Roberts et al., 2008; Seelig et al., 2017).

Data from the Centers for Disease Control suggest that $18.3 \%$ of women in the United States have experienced a lifetime rape and $44.6 \%$ have experienced other sexual violence (Black et al., 2011). Women who have recently experienced a SA might be more likely to smoke cigarettes in the aftermath of the SA as a form of self-medication to cope with negative emotions or distress (Gehricke et al., 2007; Khantzian, 1997). In a longitudinal study examining cigarette smoking among recent SA victims, two classes of post-SA smoking were identified: 1) moderate smoking with a slight decline over time, and 2) heavy smoking with a slight increase over time (Amstadter et al., 2009). White participants and those who had been injured during the SA were more likely to be in the heavy smoking trajectory, whereas those with higher distress [measured in Subjective Units of Distress (SUDs)] following a SA exam were less likely to be in the heavy smoking trajectory (Amstadter et al., 2009). 
Given heightened risk for smoking following SA and the known negative health effects of smoking (Jamal, 2016), efforts to intervene and reduce smoking following SA are critical. Resnick and colleagues developed a brief video intervention that could be delivered to recent SA victims seeking a sexual assault medical forensic exam (SAMFE) to prevent post-SA mental health and substance use problems (Resnick, Acierno, Amstadter, Self-Brown, \& Kilpatrick, 2007; Resnick, Acierno, Waldrop, et al., 2007). Specifically, the Prevention of Post-Rape Stress (PPRS) video, which presents recent SA victims with information about the SAMFE to help alleviate concerns about exam procedures along with psychoeducation and non-substance use coping strategies (Resnick, Acierno, Amstadter, et al., 2007). A shortened (9-minute) version of the PPRS targets problematic avoidance by encouraging exposure to non-dangerous SA-related cues and engagement in activities that are incongruent with substance use. A randomized controlled trial examining the efficacy of PPRS compared to treatment as usual (TAU) conducted among 268 recent SA victims indicated reduced frequency of post-SA marijuana use among women who reported recent pre-SA marijuana use (Resnick, Acierno, Amstadter, et al., 2007). More recently, the PPRS was compared to TAU and an active control condition called the Pleasant Imagery and Relaxation Information (PIRI), a video of equivalent length to the PPRS that provides instruction in relaxation, with regard to substance use outcomes. Relative to TAU, the PPRS was associated with reduced alcohol use over 6-month follow-up for minority women and those who reported pre-SA binge drinking; the PPRS also was associated with reduced marijuana use over 6-month follow-up for those with a prior SA history and those who reported pre-SA marijuana use (Walsh et al., 2017). It is possible these effects also may extend to smoking, but this hypothesis has yet to be explored. A brief video presented in the ED could have a large public health benefit if it was associated with decreases in smoking with minimal cost for dissemination.

Using the same data (Walsh et al., 2017), the current study examined whether a post-SA video intervention (PPRS) delivered in the ED at the time of the SAMFE was associated with changes in smoking compared to an active video control, PIRI, and TAU. Consistent with previous work (Walsh et al., 2017), it was hypothesized that PPRS would be associated with less smoking over a 6-month follow-up period after the SAMFE compared to both PIRI and TAU. The current study also attempted to replicate and extend prior work (Amstadter et al., 2009) by examining correlates of any smoking. Because Amstadter and colleagues (2009) found that white participants were more likely to belong to the heavy smoking trajectory following SA, it was hypothesized that white participants would evidence increases in smoking over time relative to minority participants. Additionally, because Amstadter and colleagues (2009) found that those who reported greater distress at the SAMFE were less likely to be in the heavy smoking trajectory, it was hypothesized that more distressed participants (as indicated by higher SUDS) would show decreases in smoking over time relative to those who were less distressed at the SAMFE. 


\section{METHODS}

\subsection{Participants}

Girls and women age 15 years or older $(\mathrm{N}=711)$ who were recent victims of SA (rape, suspected rape or attempted rape) and who participated in a SAMFE within 7 days of assault at one of two medical centers in a Midwestern metropolitan area were screened for inclusion. As depicted in the CONSORT flow diagram (Figure 1), 466 were excluded because they declined to participate $(n=209)$, did not meet inclusion criteria $(n=231)$, or had technical/logistical problems $(n=26)$. Of the 245 who met inclusion criteria, 233 completed the condition to which they were randomly assigned: PPRS $(n=77)$, PIRI ( $n=$ $77)$, and TAU $(n=79)$. Of the 233 participants, $154(66 \%)$ completed one or more follow-up assessments (54 in PPRS, 48 in PIRI, 52 in TAU) targeted at 1.5, 3, and 6 months after the SAMFE. The three treatment groups did not differ on age, minority status, marital status, education, household income, or employment.

\subsection{Measures}

Demographics.-Participants were asked about age (years), race (Black, white, Asian, Native American, mixed race) and ethnicity (Hispanic, non-Hispanic), marital status (married/cohabitating vs single/divorced/separated/widowed), years of education ( $<\mathrm{HS}$ diploma, HS diploma/so me college, college or beyond), household income $(<\$ 25,000$, $\$ 25-50,000,>\$ 50,000)$, and employment outside the home (yes/no). Due to limited power to examine differences between racial and ethnic groups, race/ethnicity was recoded into minority (Black, Asian, Native American, mixed race, Hispanic) vs. non-minority (white).

Cigarette smoking.-Participants self-reported on smoking in the year prior to the SA, the two weeks prior to the SA, and the two weeks prior to each follow-up assessment. First, at T1 participants were asked "In the 12 months before the assault, did you smoke cigarettes everyday, some days, or not at all?" Those who reported smoking some days or everyday in the 12 months prior to the assault were then asked "Thinking back to the 14 days before the assault, on how many days did you smoke cigarettes?" and "On days when you smoked during the 14 days before the assault, on average how many cigarettes did you smoke a day?" Consistent with past work (Saddleson et al., 2016), responses to these two questions were multiplied to determine the number of cigarettes smoked the two weeks prior to the SA. To obtain past two-week smoking estimates at T1-T3, they were asked "On how many of the past 14 days did you smoke cigarettes?" and "On days when you smoked during the past 14 days, on average how many cigarettes did you smoke a day?" Responses were multiplied to determine the number of cigarettes smoked in the past two weeks at each time point.

Intervention conditions.-The current study evaluated the effectiveness of a 9-minute ${ }^{1}$ video intervention, Prevention of Post-Rape Stress (PPRS), that was designed to reduce future emotional problems and substance abuse by providing instruction on proper

\footnotetext{
${ }^{1}$ A small proportion $(n=28 ; 18 \%)$ of participants received longer (18-minute) versions of the intervention and active control videos that were shown prior to the SAFME and included either the PPRS or PIRI video plus information about the examination. There were no differences among those who received the shorter and longer versions of the intervention and active control in pre-examination
} 
implementation of self-directed exposure exercises, methods to recognize and terminate inappropriate avoidance, and strategies to engage in activities that specifically did not involve alcohol or drug use and avoid situations or cues that have been triggers for use. This intervention was compared to a 9-minute "active comparison" video, Pleasant Imagery and Relaxation Instruction (PIRI), which was edited for content and length from Relax $\odot$, David Garrigus Productions, and provided instruction in diaphragmatic breathing, muscle relaxation, use of words such as relax paired with exhalation, and pleasant nature-related imagery and sounds. PPRS and PIRI also were compared to Treatment As Usual (TAU), which involved completion of a SA examination performed by a Sexual Assault Nurse Examiner.

SA-related distress.-Prior to the SAMFE exam, participants reported subjective units of distress (SUDS) on a scale from 0 (no distress) to 100 (unbearable distress). SUDS are commonly used during exposure tasks in cognitive behavioral therapy for anxiety and related disorders or during stress-inducing tasks to allow participants to report acute distress (e.g., Benjamin et al., 2010; Marx et al., 2012; McLean \& Hope, 2010). SUDS also have been used in a prior study of rape victims presenting to the ED (Amstadter et al., 2009).

\subsection{Procedures}

Procedures were approved by two University and two affiliated hospital Institutional Review Boards. Between May 2009 and December 2013, SAMFE participants provided written informed consent to participate in the study and allow access to both medical records and self-report information. Participants were randomly assigned to one of three intervention conditions and then completed three structured telephone follow-up interviews targeted at $1.5,3$, and 6 months post-SA conducted by Counseling Psychology doctoral students. Nurses administering the protocol and doctoral students conducting the follow-ups were blind to study condition. Participants were compensated for their time. More detailed methods can be found elsewhere (Walsh et al., 2017).

\subsection{Statistical Analysis}

Participants provided follow-up data at three time points. A total of 154 participants provided data at Time $1(\mathrm{~T} 1), 1.90(S D=.83)$ months after the SAMFE, 135 participants (87.7\% of T1 participants) provided data at Time $2(\mathrm{~T} 2), 3.59(S D=0.84)$ months after the SAMFE, and 121 (78.6\% of T1 participants) provided data at Time 3 (T3), 6.51 ( $S D=1.85$ ) months after the SAMFE. Those who did and did not provide any follow-up data did not differ on age $(F(1,232)=.48, p=.62)$, minority status $\left.\chi^{2}(1, \mathrm{~N}=232)=1.72, p=.42\right)$, distress at the $\operatorname{ED}(F(1,232)=.24, p=.79)$, or intervention condition $\left(\chi^{2}(d f=2)=3.36, p\right.$ $=.50)$. Similarly, those who provided data at $\mathrm{T} 2$ and $\mathrm{T} 3 \mathrm{did}$ not differ from those who did not on age, minority status, distress at the ED, intervention condition. Given that there were no systematic differences between those who did and did not provide data at certain time points, data were considered missing at random.

PANAS, $F(1,141)=0.65, p=0.42$; post-examination PANAS, $F(1,141)=0.01, p=0.91)$; or assigned treatment condition, $\chi^{2}(\mathrm{df}=2)$ $=1.08, p=0.58$. 
Analyses were conducted in multiple steps. Descriptive and correlational analyses were conducted in SPSS version 23, while latent growth analyses were conducted in Mplus version 8.0. First, the prevalence of any pre-or post-SA smoking was computed and analysis of variance (ANOVA) or chi square tests were used to examine differences in demographics, SA-related distress, prior history of assault, and intervention condition among those who did and did not report smoking. Second, descriptive data regarding smoking at each time point were presented. Third, correlations among study variables were examined. Fourth, latent growth curve analysis (LGCA) was used to model the intercept and slope of smoking in the entire sample. Time points used for analysis included baseline (pre-SA smoking assessed at T1), T1 (1.9 months), T2 (3.6 months), and T3 (6.5 months). An initial unconditional model was fit specifying pre-SA smoking as the intercept and smoking at each follow-up as time since the ED visit. A conditional model regressing the intercept of smoking on demographic characteristics that were significant in bivariate analyses and the slope of smoking on intervention condition, ED SUDS, and significant demographics was then fit. The intercept was not regressed on intervention condition or ED SUDS because it reflected pre-SA smoking. Because the smoking variables contained a large number of zeroes (for those who never smoked) and were also non-normal and overdispersed, they were identified as negative binomial when the growth curve model was fit. Traditional model fit statistics (CFI,

RMSEA) were not available with this analysis; thus, Bayesian Information Criterion (BIC) values were considered and unstandardized parameter estimates, standard errors, and standardized estimates were interpreted. Maximum likelihood estimation with robust standard errors was used to handle missing data.

\section{RESULTS}

\subsection{Descriptive data}

Of the 154 SA victims who provided any follow-up data, $68.8 \%(n=106)$ reported smoking in the two weeks prior to the SA or at one of the three follow-ups (Table 1). Smokers did not differ from non-smokers on age, minority status, marital status, or pre-exam SUDS; however, they were less likely than non-smokers to be employed outside the home and to have a college degree, and they were more likely than non-smokers to make less than $\$ 25,000$ annually.

Descriptive smoking data in the overall sample and by study condition by each time point are presented in Table 2. Study conditions only differed significantly in number of days of smoking or average number of cigarettes smoked at T1. Approximately $2 \%(n=2)$ of those who reported any smoking in the 2 weeks prior to the SA did not smoke over follow-up. However, $20 \%(n=12)$ of those who did not smoke in the two weeks prior to the SA smoking reported smoking over follow-up. When pre-rape smoking was broadened to the year prior to the rape, $19 \%(n=11)$, initiated smoking at follow-up.

Correlations among the study variables are presented in Table 3 . The TAU vs PPRS comparison was positively associated with smoking at T1 ( 2 months post-assault) but not at the other two follow-ups. The pre- and post-smoking variables were all moderately to strongly correlated with each other (Is range from .54-.84). However, only SUDs at the ED, age, education, and income were significantly correlated with smoking. Specifically, women 
who were more distressed at the ED and older women reported more smoking whereas those with more education and higher income reported less smoking.

\subsection{Latent Growth Curve Modeling}

An unconditional latent growth curve model specifying the intercept as smoking reported in the 2 weeks prior to the ED and slope as time since the ED visit revealed a significant positive intercept and negative slope (Table 4), suggesting that smoking declined over follow-up on average. There was significant variance around both the intercept and slope. A conditional model regressing the intercept on significant demographic variables and slope on the intervention conditions, ED SUDS, and significant demographics indicated that ED SUDS, education and income were significantly associated with the intercept of smoking. Specifically, those who reported higher distress at the ED reported smoking more in the two weeks prior to the SA compared to those who were less distressed, whereas those with higher education and income reported smoking less prior to the SA than those with less education and lower income. The TAU vs PPRS comparison significantly predicted the slope of smoking such that individuals in the TAU condition increased in smoking over time compared to those in the PPRS condition. Additionally, those who reported working outside the home had a steeper decline in smoking over the course of the study relative to those who did not.

\section{DISCUSSION}

The current study extends previous work by examining the efficacy of the PPRS, a brief intervention designed to reduce substance use and mental disorders that was delivered to SA victims in the ED, on cigarette smoking after a recent sexual assault. The PPRS has numerous benefits including ease of dissemination within an ED setting, low costs, and potential to decrease a number of substance use and mental health symptoms associated with sexual assault (Miller, Cranston, Davis, Newman, \& Resnick, 2015; Resnick, Acierno, Amstadter, et al., 2007; Resnick, Acierno, Waldrop, et al., 2007). The current study found that the PPRS mitigated cigarette smoking among participants who had received a SAMFE. Specifically, although smoking decreased on average for all groups, participants in TAU reported increases in cigarette smoking at the initial follow-up, while those in PPRS did not. No differences were found between PPRS and the active control condition, PIRI, on cigarette smoking over follow-up. The PPRS video content that focuses on coping using means other than substance use may be effective for cigarette smoking in addition to previously found effects for marijuana use (Resnick, Acierno, Amstadter, et al., 2007) and alcohol use (Walsh et al., 2017).

Of note, more than two-thirds (68.8\%) of women who presented for a SAMFE and provided follow-up data reported smoking prior to or after the SA. Additionally, a substantial proportion (19\%) of women who reported that they had not smoked in the year prior to the SA reported smoking at some point during follow-up, suggesting that sexual assault may serve as a catalyst for some women to either begin smoking or start smoking again if they had previously quit. From a public health perspective, this is concerning given the detrimental health effects of smoking (Health \& Services, 2014). Additionally, higher 
distress at the ED was associated with smoking more in the two weeks prior to the SA, suggesting that those who were more distressed at the ED may have been more distressed prior to the SA and thus smoked more to cope. It also is possible that this group represented more nicotine-dependent individuals prior to the SA. When exposed to SA and faced with the prospect of a SAMFE, this group may have experienced more withdrawal and craving that heightened their distress. Indeed, laboratory stressors administered to smokers have been shown to increase withdrawal, craving, and subjective distress (Kotlyar et al., 2011); thus, it is conceivable that a real-world traumatic event like SA might produce similar effects. Consistent with prior research (Barbeau, Krieger, \& Soobader, 2004), lower education and income were associated with increased smoking. Women who experience SA who are already disadvantaged educationally and economically may represent an underserved population with regard to smoking cessation needs. The utility of this brief intervention video is promising; however, future research could focus on better identifying those who may struggle most with coping and refer them to intensive smoking cessation treatment.

\subsection{Limitations}

Findings should be considered in the context of study limitations. First, although it is a strength that the current study compared PPRS to both PIRI and TAU, the sample size for each treatment condition was small and results should be replicated in larger samples. Second, because smoking was not assessed at the ED, the current study focused on participants with at least one follow-up. Findings may have differed if analyses focused on all women enrolled at the ED, and assessing pre-rape smoking retrospectively at $\mathrm{T} 1$ may have resulted in reports of smoking that were biased by recall or by the effects of the treatment. Third, despite established links between PTSD and smoking (Kearns et al., 2018), the current study was underpowered to examine whether reductions in PTSD symptoms explained reductions in smoking. Fourth, the current study only included women so results may not generalize to men or transgender individuals. Similarly, although the demographics of the current sample are consistent with epidemiologic studies on SA victims presenting to the ED (Avegno, Mills, \& Mills, 2009), our sample was relatively low income, unemployed, and single, making generalizability of the findings to other victims unclear. Fifth, the exclusion criteria (e.g., non-English speaking or presenting with serious injuries, psychological distress, acute intoxication) may have biased the sample towards including healthier individuals and impacted the results. Finally, the current study did not assess other types of tobacco use or vaping, which is on the rise among adolescents and young adults (Jamul et al., 2017); future studies should examine whether SA is similarly associated with these behaviors.

\subsection{Conclusions}

The current study highlights the importance of studying smoking among recent SA victims as $20 \%$ who had not smoked in the two weeks prior to the assault initiated or resumed smoking in the 6-month period following the assault. Importantly, these findings also suggest that the PPRS video has utility for preventing post-SA increases in smoking among recent SA victims. This finding is promising in that the PPRS video is brief, and can be widely disseminated in the ED with minimal cost. 


\title{
Acknowledgments
}

\author{
Role of Funding Source
}

The study was conducted with support from National Institute on Drug Abuse Grant DA023099. Manuscript preparation was supported by National Institutes of Health Grants MH107641, MH107641-02S1, DA036213, and T32-MH018869. The funding sponsor had no role in study design, collection, analysis, or interpretation of data, writing the manuscript, or the decision to submit the manuscript for publication.

\section{References}

Amstadter AB, Resnick HS, Nugent NR, Acierno R, Rheingold AA, Minhinnett R, \& Kilpatrick DG (2009). Longitudinal trajectories of cigarette smoking following rape. Journal of Traumatic Stress: Official Publication of The International Society for Traumatic Stress Studies, 22(2), 113-121.

Anda RF, Croft JB, Felitti VJ, Nordenberg D, Giles WH, Williamson DF, \&Giovino GA (1999). Adverse childhood experiences and smoking during adolescence and adulthood. Jama, 282(17), 1652-1658. [PubMed: 10553792]

Avegno J, Mills TJ, \& Mills LD (2009). Sexual assault victims in the emergency department: analysis by demographic and event characteristics. The Journal of Emergency Medicine, 37(3), 328-334. [PubMed: 18394848]

Barbeau E, Krieger N, \& Soobader M-J (2004). Erratum: Working class matters: Socioeconomic disadvantage, race/ethnicity, gender, and smoking in NHIS 2000 (American Journal of Public Health (2004) 94 (296-278)). American Journal of Public Health, 94(8), 1295-1295. [PubMed: 15284027]

Benjamin CL, O'Neil KA, Crawley SA, Beidas RS, Coles M, \& Kendall PC (2010). Patterns and predictors of subjective units of distress in anxious youth. Behavioural and cognitive psychotherapy, 38(4), 497-504. [PubMed: 20509987]

Black MC, Basile KC, Breiding MJ, Smith SG, Walters ML, Merrick MT, \& Stevens MR (2011). The national intimate partner and sexual violence survey: 2010 summary report. Atlanta, GA: National Center for Injury Prevention and Control, Centers for Disease Control and Prevention, 19, 39-40.

Cisler JM, Amstadter AB, Begle AM, Resnick HS, Danielson CK, Saunders BE, \& Kilpatrick DG (2011). A prospective examination of the relationships between PTSD, exposure to assaultive violence, and cigarette smoking among a national sample of adolescents. Addictive behaviors, 36(10), 994-1000. [PubMed: 21719204]

Cloutier S, Martin SL, \& Poole C (2002). Sexual assault among North Carolina women: prevalence and health risk factors. Journal of Epidemiology \& Community Health, 56(4), 265-271. [PubMed: 11896133]

Edwards VJ, Anda RF, Gu D, Dube SR, \& Felitti VJ (2007). Adverse childhood experiences and smoking persistence in adults with smoking-related symptoms and illness. The Permanente Journal, 11(2), 5.

Ford ES, Anda RF, Edwards VJ, Perry GS, Zhao G, Li C, \& Croft JB (2011). Adverse childhood experiences and smoking status in five states. Preventive medicine, 53(3), 188-193. [PubMed: 21726575]

Gehricke J-G, Loughlin SE, Whalen CK, Potkin SG, Fallon JH, Jamner LD, ... Leslie FM (2007). Smoking to self-medicate attentional and emotional dysfunctions. Nicotine \& tobacco research, 9(Suppl_4), S523-S536. [PubMed: 18067030]

Hapke U, Schumann A, Rumpf H-J, John U, Konerding U, \& Meyer C (2005). Association of smoking and nicotine dependence with trauma and posttraumatic stress disorder in a general population sample. The Journal of nervous and mental disease, 193(12), 843-846. [PubMed: 16319709]

Health, U. D. o., \& Services, H. (2014). The health consequences of smoking - 50 years of progress: a report of the Surgeon General. Atlanta, GA: US Department of Health and Human Services, Centers for Disease Control and Prevention, National Center for Chronic Disease Prevention and Health Promotion, Office on Smoking and Health, 17.

Jamal A (2016). Current cigarette smoking among adults-United States, 2005-2015. MMWR. Morbidity and mortality weekly report, 65 . 
Jarmul S, Aherrera A, Rule AM, Olmedo P, Chen R, \& Navas-Acien A (2017). Lost in e-cigarette clouds: a culture on the rise. Am J Public Health, 107, 265-266. [PubMed: 27997237]

Kearns NT, Carl E, Stein AT, Vujanovic AA, Zvolensky MJ, Smits JA, \& Powers MB (2018). Posttraumatic stress disorder and cigarette smoking: A systematic review. Depression and anxiety.

Khantzian EJ (1997). The self-medication hypothesis of substance use disorders: a reconsideration and recent applications. Harvard review of psychiatry, 4(5), 231-244. [PubMed: 9385000]

Kotlyar M, Drone D, Thuras P, Hatsukami DK, Brauer L, Adson DE, \& al'Absi M (2011). Effect of stress and bupropion on craving, withdrawal symptoms, and mood in smokers. Nicotine \& tobacco research, 13(6), 492-497. [PubMed: 21378081]

Marx BP, Bovin MJ, Suvak MK, Monson CM, Sloan DM, Fredman SJ, ... \& Keane TM (2012). Concordance between physiological arousal and subjective distress among Vietnam combat veterans undergoing challenge testing for PTSD. Journal of Traumatic Stress, 25(4), 416-425. [PubMed: 22848013]

Matthews AK, Cho YI, Hughes TL, Wilsnack SC, Aranda F, \& Johnson T (2017). The Effects of Sexual Orientation on the Relationship Between Victimization Experiences and Smoking Status Among US Women. Nicotine and Tobacco Research, 20(3), 332-339.

McLean CP, \& Hope DA (2010). Subjective anxiety and behavioral avoidance: Gender, gender role, and perceived confirmability of self-report. Journal of Anxiety Disorders, 24(5), 494-502. [PubMed: 20381303]

Miller KE, Cranston CC, Davis JL, Newman E, \& Resnick H (2015). Psychological outcomes after a sexual assault video intervention: A randomized trial. Journal of forensic nursing, 11(3), 129-136. [PubMed: 26291847]

Nemeth JM, Bonomi AE, Lu B, Lomax RG, \& Wewers ME (2016). Risk factors for smoking in rural women: the role of gender-based sexual and intimate partner violence. Journal of Women's Health, 25(12), 1282-1291.

Resnick HS, Acierno R, Amstadter AB, Self-Brown S, \& Kilpatrick DG (2007). An acute post-sexual assault intervention to prevent drug abuse: Updated findings. Addictive behaviors, 32(10), 20322045. [PubMed: 17275198]

Resnick HS, Acierno R, Waldrop AE, King L, King D, Danielson C, ... Kilpatrick D (2007). Randomized controlled evaluation of an early intervention to prevent post-rape psychopathology. Behaviour research and therapy, 45(10), 2432-2447. [PubMed: 17585872]

Roberts ME, Fuemmeler BF, McClernon FJ, \& Beckham JC (2008). Association between trauma exposure and smoking in a population-based sample of young adults. Journal of Adolescent Health, 42(3), 266-274. [PubMed: 18295135]

Saddleson M, Kozlowski L, Giovino G, Homish G, Mahoney M, \& Goniewicz M (2016). Assessing 30-day quantity- frequency of US adolescent cigarette smoking as a predictor of adult smoking 14 years later. Drug and alcohol dependence, 162, 92-98. [PubMed: 26987520]

Seelig AD, Rivera AC, Powell TM, Williams EC, Peterson AV, Littman AJ, .. Boyko EJ (2017). Patterns of smoking and unhealthy alcohol use following sexual trauma among US Service members. Journal of traumatic stress, 30(5), 502-511. [PubMed: 28906037]

Vlahov D, Galea S, Ahern J, Resnick H, Boscarino JA, Gold J, ... Kilpatrick D (2004). Consumption of cigarettes, alcohol, and marijuana among New York City residents six months after the September 11 terrorist attacks. The American journal of drug and alcohol abuse, 30(2), 385-407. [PubMed: 15230082]

Walsh K, Elliott JC, Shmulewitz D, Aharonovich E, Strous R, Frisch A, ... Hasin D (2014). Trauma exposure, posttraumatic stress disorder and risk for alcohol, nicotine, and marijuana dependence in Israel. Comprehensive psychiatry, 55(3), 621-630. [PubMed: 24387979] 


\section{Highlights}

- $\quad$ RCT tested a brief video intervention among rape victims in the emergency room

- $67 \%$ of rape victims reported smoking prior to or after the rape

- Of women who did not smoke in the year before the rape, $19 \%$ smoked following the rape

- The video mitigated smoking relative to treatment as usual 


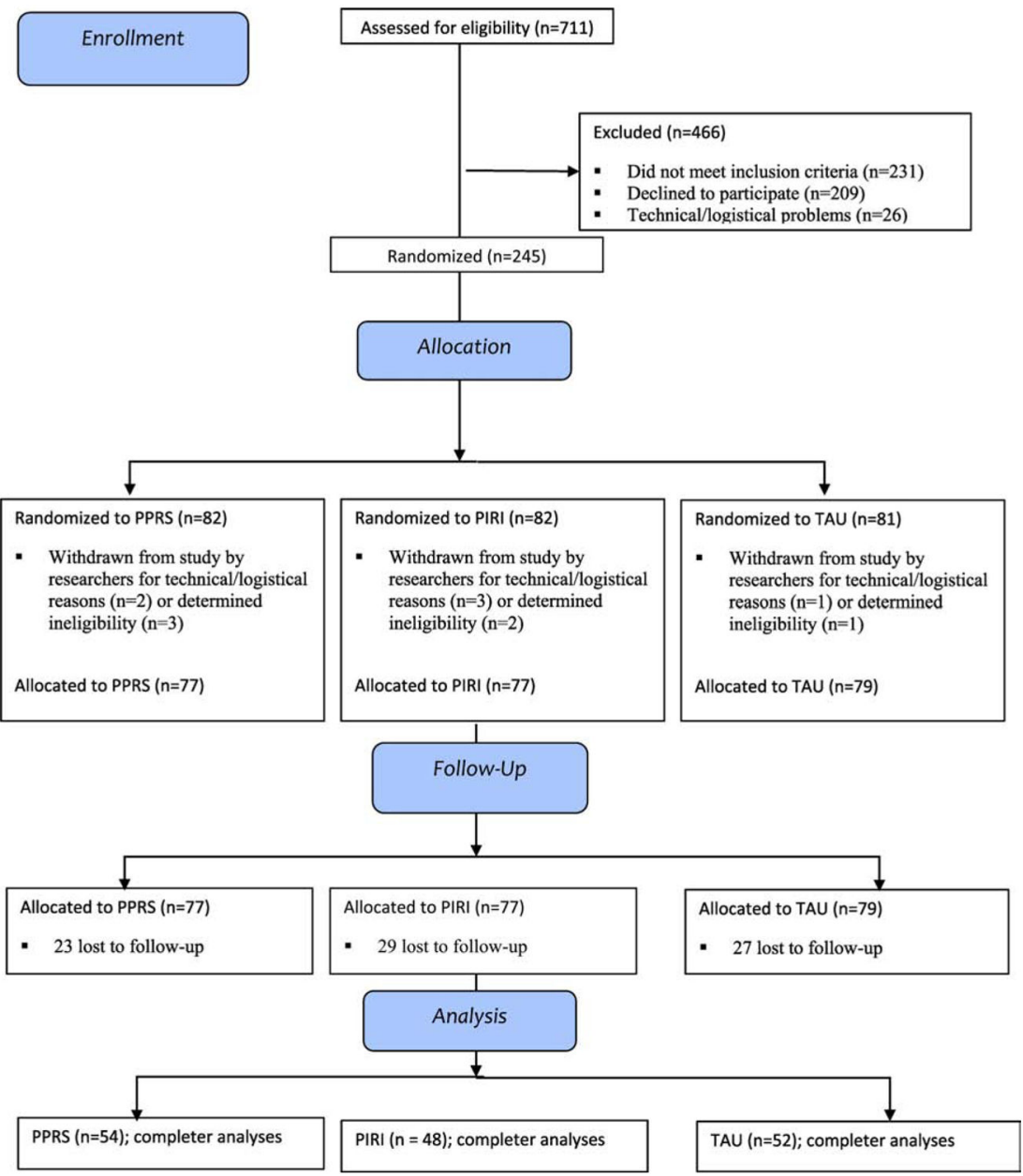

Fig. 1.

Consort Flow Diagram. 


\section{Table 1}

Baseline Characteristics of Those With and Without Any Smoking

\begin{tabular}{|c|c|c|c|}
\hline & $\begin{array}{l}\text { No smoking } \\
(31.2 \%, n=48)\end{array}$ & $\begin{array}{l}\text { Any smoking } \\
(68.8 \%, n=106)\end{array}$ & $\mathbf{F} / \chi^{2}$ \\
\hline Age $($ range $=15-55)$ & $28.1(9.6)$ & $27.3(9.2)$ & $F(1,153)=0.26$ \\
\hline Minority status & $50.0 \%(\mathrm{n}=24)$ & $60.4 \%(n=64)$ & $\chi^{2}(1)=1.45$ \\
\hline Married/cohabitating & $12.5 \%(n=6)$ & $14.2 \%(\mathrm{n}=15)$ & $\chi^{2}(1)=0.08$ \\
\hline Employed outside home & $54.2 \%(\mathrm{n}=26)$ & $25.5 \%(\mathrm{n}=27)$ & $\chi^{2}(1)=12.05^{* * *}$ \\
\hline Education & & & $\chi^{2}(2)=17.01^{* * *}$ \\
\hline$<$ HS graduate & $8.3 \%(n=4)$ & $29.2 \%(\mathrm{n}=31)$ & \\
\hline HS/some college & $70.8 \%(\mathrm{n}=34)$ & $67.0 \%(\mathrm{n}=71)$ & \\
\hline College/graduate degree & $20.8 \%(\mathrm{n}=10)$ & $3.8 \%(n=4)$ & \\
\hline Income & & & $\chi^{2}(2)=21.98^{* * *}$ \\
\hline$<\$ 25,000$ & $61.9 \%(\mathrm{n}=26)$ & $93.7 \%(\mathrm{n}=89)$ & \\
\hline$\$ 25,000-\$ 50,000$ & $28.6 \%(\mathrm{n}=12)$ & $5.3 \%(\mathrm{n}=5)$ & \\
\hline$>\$ 50,000$ & $9.5(n=4)$ & $1.1 \%(\mathrm{n}=1)$ & \\
\hline Pre-exam SUDS & $70.7(26.4)$ & $71.6(27.1)$ & $F(1,145)=0.04$ \\
\hline
\end{tabular}



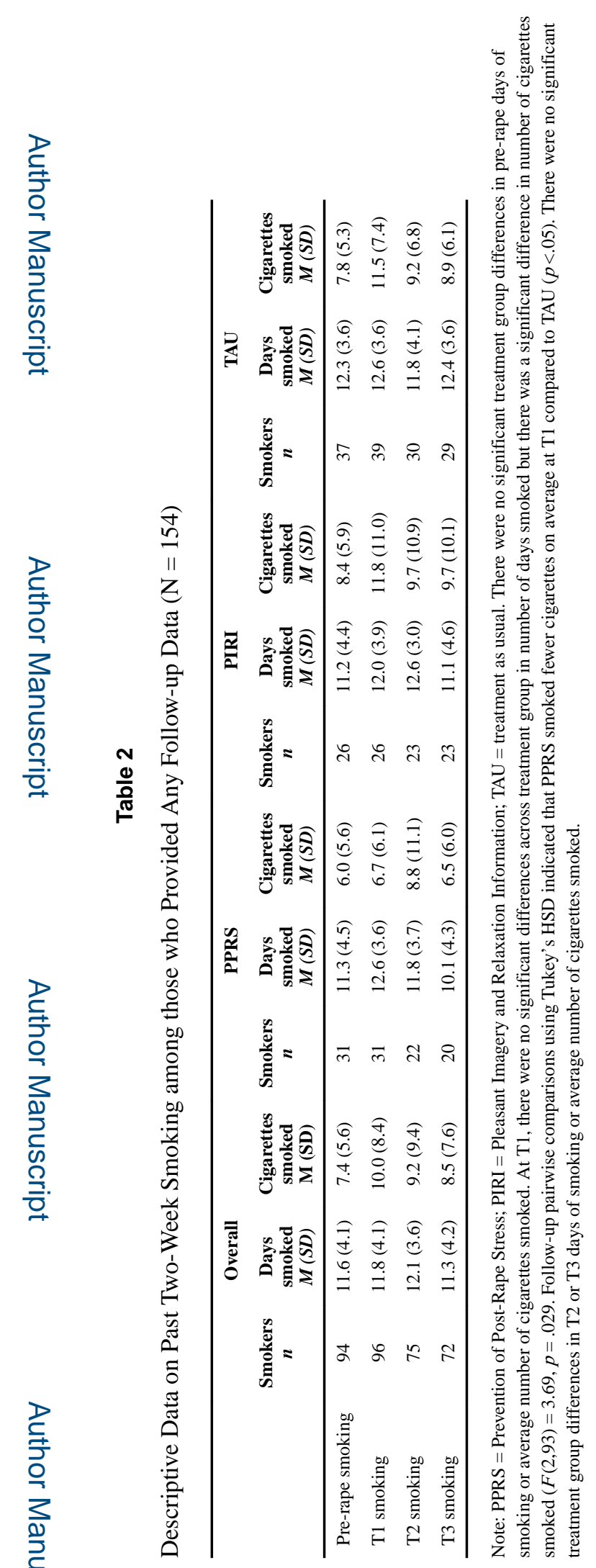

Addict Behav. Author manuscript; available in PMC 2021 January 01. 


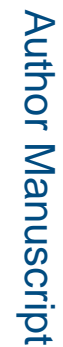

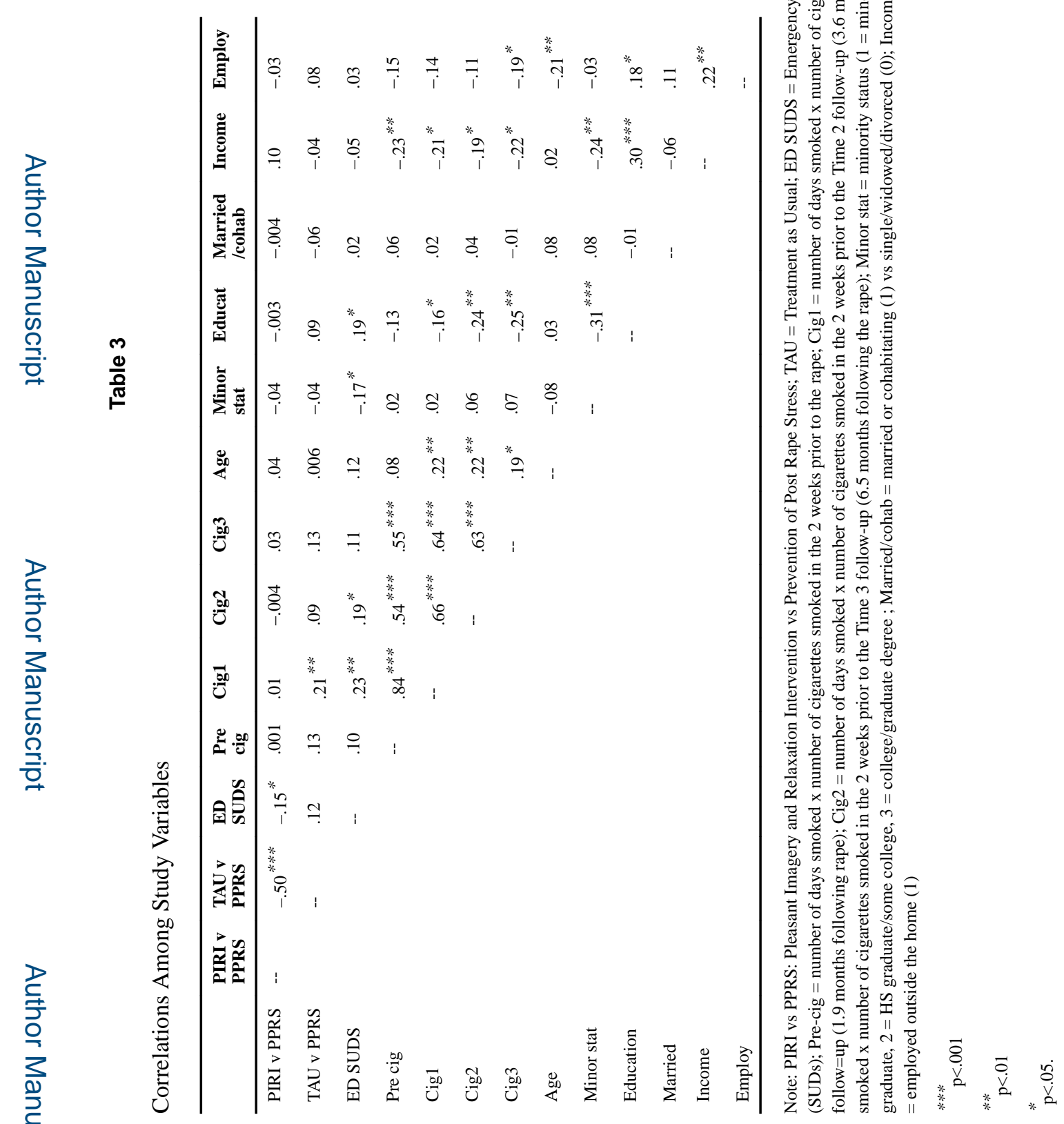

Addict Behav. Author manuscript; available in PMC 2021 January 01. 


\section{Table 4}

Latent Growth Curve Model Estimating the Effect of Intervention Conditions on Smoking Following Sexual Assault

\begin{tabular}{lcccc}
\hline & $\begin{array}{c}\text { Intercept } \\
\text { Estimate (SE) }\end{array}$ & $\begin{array}{c}\text { Standardized } \\
\text { Estimate (SE) }\end{array}$ & $\begin{array}{c}\text { Slope } \\
\text { Estimate (SE) }\end{array}$ & $\begin{array}{c}\text { Standardized } \\
\text { Estimate (SE) }\end{array}$ \\
\hline Unconditional Model & $3.03(0.11)^{* * * * * *}$ & $.99(.08)^{* * *}$ & $-0.09(0.03)^{* * *}$ & $-0.72(0.18)$ \\
Variance & $9.41(0.95)^{* * *}$ & 1.0 & $0.02(0.008)^{*}$ & 1.0 \\
Conditional Model & -- & -- & $0.07(0.07)$ & $0.15(0.15)$ \\
PIRI (1) vs PPRS (0) & -- & -- & $0.16(0.08)^{*}$ & $0.35(0.14)$ \\
TAU (1) vs PPRS (0) & $0.02(.01)^{*}$ & $0.16(0.08)^{*}$ & $.001(.001)$ & $-0.04(0.13)$ \\
ED SUDS & $0.17(0.42)$ & $0.04(0.08)$ & $0.10(0.06)$ & $0.33(0.21)$ \\
Age & $-1.25(0.57)^{*}$ & $-0.19(0.09)$ & $-0.07(0.06)$ & $-0.18(0.14)$ \\
Education & $-2.71(0.78)^{* * *}$ & $-0.36(0.09)^{* * *}$ & $-0.09(.09)$ & $-0.19(0.15)$ \\
Income & $-0.83(0.61)$ & $-0.11(0.08)$ & $-0.19(0.06)$ & $-0.41(0.13)$ \\
\hline Employed outside home & &
\end{tabular}

Note: PIRI vs PPRS: Pleasant Imagery and Relaxation Intervention vs Prevention of Post Rape Stress; TAU = Treatment as Usual; ED SUDS = Emergency Department (ED) Subjective Units of Distress (SUDs); --not estimated

p $<.05$

** $\mathrm{p}<.01$

* ${ }^{*}<.001$ 